\title{
Impactos da Área de Liure Comércio das Américas (Alca), com gradual desgravação tarifária, na economia brasileira
}

Edson Zambon Monte Economista do Banco de Desenvolvimento do Espírito Santo (Bandes)

Erly Cardoso Teixeira

Professor titular do Departamento de Economia Rural da Universidade Federal de Viçosa

\section{Palauras-chave}

Alca, desgravação tarifária, Brasil, GTAP.

Classificação JEL F15, C68, Q17.

Key words

FTA $A$, tariff reduction, Brazil, GTAP.

JEL Classification F15, C68, Q17.

\section{Resumo}

As barreiras comerciais protegem as economias da concorrência internacional, mas distorcem o comércio entre elas e reduzem os benefícios que poderiam advir dos acordos de livre comércio. O objetivo deste trabalho é avaliar os impactos da criação da Área de Livre Comércio das Américas (Alca), com desgravação tarifária gradual, nos principais indicadores da economia brasileira. $\mathrm{O}$ modelo de equilíbrio geral do Global Trade Analysis Project (GTAP) é adotado como instrumento metodológico. Somente alguns setores do agronegócio mostraram-se competitivos. O setor de manufaturados não foi competitivo em nenhum dos cenários, e os setores florestais, têxteis e calçados tiveram aumento significativo na produção e na exportação. Os indicadores de crescimento econômico e bem-estar foram favoráveis ao Brasil, em todos os cenários, mesmo que o crescimento tenha sido pequeno.

\section{Abstract}

Commercial barriers protect economies from international competition; however they distort the commercial relationship between them, and reduce the benefits that could result from free trade. The objective of this paper is to determine the impacts that the Free Trade Area of the Americas (FTAA), with its progressive tariff reduction, would have on the Brazilian economy. The Global Trade Analysis Project (GTAP), general equilibrium model, is used as a methodological instrument. Few agribusiness sectors would be competitive under the FTAA. The manufacturing sector would not be competitive under any of the scenarios. Industries like forestry, textiles and footwear would undergo a significant increase in production and exports. Brazilian Economic growth and welfare indicators are favorable to Brazil in all scenarios, even through growth was modest. 


\section{1_ Introdução}

Os países do continente americano apresentam grande assimetria, no que tange às políticas protecionistas, ou seja, alguns países impõem barreiras comerciais mais elevadas do que outros. Se, por um lado, essas barreiras protegem alguns setores da concorrência internacional, por outro, distorcem as relações comerciais entre essas economias, além de reduzirem os benefícios que poderiam advir de maior relacionamento comercial.

Sabe-se que a criação de uma área de livre comércio pode afetar vários indicadores econômicos de um país e que, apesar de levarem a melhorias desses, também geram custos para alguns setores, principalmente para aqueles ineficientes, recorrentes das alterações nas próprias variáveis econômicas e ou setoriais que podem afetar os elos constitutivos de uma economia. Como exemplos, têm-se alguns trabalhos, como os desenvolvidos por Valverde e Teixeira (1997), Figueiredo, Ferreira e Teixeira. (2001), Cypriano e Teixeira (2003), sobre acordos de livre comércio, os quais demonstram que no Brasil o setor do agronegócio é mais competitivo e gera mais ganho comercial do que o de manufaturados, embora nem sempre seja verificado maior crescimento econômico e aumento no bem-estar da economia brasileira, quando da formação de áreas de livre comércio.

As áreas de livre comércio regionais são negociadas com maior facilidade do que os acordos multilaterais; porém, ainda há muitas dificuldades de implementação desses blocos, dadas as restrições impostas pelos países desenvolvidos aos países em desenvolvimento. Mesmo assim, cada vez mais ganha ênfase a união regional entre nações, a qual possibilite mercados alternativos a produtos tradicionais e abra espaço para outros bens e serviços.

Nesse contexto, em 1994 foi assinada, por 34 países da América, a carta de intenções que criou as diretrizes para implementação da Área de Livre Comércio das Américas (Alca). A criação de um bloco de livre comércio nas Américas objetiva eliminar, gradualmente, as barreiras alfandegárias entre os países. Devido ao bloqueio econômico que sofre, imposto pelos Estados Unidos, Cuba não faz parte desse acordo.

As discussões da Alca ocorrem em nove grupos de negociação:

1. acesso a mercados;

2. agricultura;

3. serviços;

4. investimentos;

5. compras governamentais; 
6. solução de controvérsias;

7. direitos de propriedade intelectual;

8. subsídios, antidumping e medidas compensatórias;

9. políticas de concorrência.

Apesar dos esforços na tentativa de estabelecer, definitivamente, uma área de livre comércio das Américas, nos últimos anos o processo de negociação tem sido interrompido por interesses econômicos das diferentes nações participantes do acordo, principalmente pelas divergências entre as propostas apresentadas pelo North American Free Trade Agreement (Nafta), liderado pelos Estados Unidos, que tem maior interesse nos setores de serviços, investimentos, propriedade intelectual, comércio eletrônico, e aquelas postas pelos países do Mercado Comum do Sul (Mercosul), no qual está inserido o Brasil, que privilegiam o acesso a mercados, subsídios, antidumping e medidas compensatórias, solução de controvérsias e, principalmente, agricultura.

Ademais, a perspectiva de formação de uma área de livre comércio entre os países do continente americano traz à tona várias preocupações, dado que a criação do Mercosul uniu países com características histórico-culturais, políticas e socioeconômicas, de certa forma, semelhantes, fato que não acontecerá com o advento da formação da Alca.
Na Reunião do Comitê de Negociações Comerciais (CNC), que ocorreu no final de 2000, na República Dominicana, foi apresentada a primeira lista de ofertas de desgravação tarifária para os países membros da Alca. Foram definidas quatro fases para efeito de desgravação:

- primeira fase, imediata;

_ segunda fase, até cinco anos;

_ terceira fase, até 10 anos;

_ quarta fase, acima de 10 anos, ou seja, sem prazo definido.

A desgravação e os diferentes prazos têm o intuito de contemplar alguns produtos considerados sensíveis e promover a participação plena de todas as nações participantes.

Nesse processo de desgravação tarifária, as ofertas iniciais dos Estados Unidos discriminam os países do Mercosul. Apesar de considerar que todos os setores estarão sujeitos à negociação, o Brasil (Mercosul) adotou comportamento defensivo em suas ofertas, visto que viu na Alca uma ameaça, e não amplas oportunidades de novos mercados para diversos setores da economia, sobretudo no setor agrícola. As posições tomadas pelo Brasil não levam em conta os custos da ação defensiva para formação da Alca, que pode ser prejudicial à economia brasileira, especialmente para o agronegócio. 
A oferta do Mercosul (Brasil) visa à proteção dos setores ineficientes da economia brasileira, ao passo que deveria buscar oportunidades de ampliar o acesso a mercados pelos setores mais eficientes. Vale ressaltar que a criação de uma área de livre comércio abrirá novos mercados para diversos setores brasileiros; porém, para que esses setores sejam beneficiados, o governo brasileiro deverá promover políticas que desonerem o setor produtivo da alta carga tributária, da elevada taxa de juros, da rigidez do mercado de trabalho, da burocracia e do custo da ausência de infra-estrutura que incidem sobre ele, pois elevam, de forma significativa, os custos de produção.

Nas negociações da Alca, tornase essencial que o governo brasileiro dê atenção aos setores que têm maior competitividade no comércio internacional, de forma que desfrutem ao máximo dos seus benefícios. É necessário também que o Brasil dê maior relevância ao enfoque multissetorial, ou seja, buscar competitividade em outros setores, para garantir maior poder de barganha (negociação) econômico.

Valverde e Teixeira (1997), ao utilizarem o modelo GTAP e sua base de dados, segunda versão, discutiram o possível impacto da Alca no mercado inter- nacional. Os resultados para o Brasil sugerem que a Alca teria pequeno impacto, mas positivo, em todos os indicadores econômicos.

Figueiredo, Ferreira e Teixeira (2001), por meio do modelo de equilíbrio geral aplicado, GTAP, avaliaram os efeitos de possível acordo de livre comércio entre a União Européia e os países da América Latina e Caribe sobre a agricultura brasileira e européia. Nesse estudo, concluíram que os benefícios da liberalização seriam concentrados nos setores de maior vantagem comparativa, agronegócio para o Brasil e manufaturados para a União Européia, com a criação de comércio.

Cypriano e Teixeira (2001) analisaram a criação da Alca, por meio do modelo GTAP na versão 4, na perspectiva dos impactos causados no setor agroindustrial da economia brasileira e dos demais países do Mercosul. Pelo estudo, concluíram que haveria vantagens para esses países com a criação da Alca, que eliminaria ou não distorções causadas pelos subsídios à exportação e à produção, as quais são praticadas, principalmente, pelos Estados Unidos.

Fonseca e Hidalgo (2004), por meio do modelo de equilíbrio parcial de bemestar de Laird e Yeats (1986), constataram que a formação da Alca, no período 
Todos os dados, figuras e informações desta seção foram retirados e ou adaptados de Hertel e Tsigas (1997). de 1999 a 2000, levaria a um aumento das exportações agrícolas brasileiras, principalmente de café, soja e carnes.

Gurgel e Campos (2003a, 2003b), em seus estudos sobre os impactos da formação da Alca sobre a economia brasileira, demonstraram que a completa eliminação de tarifas às importações entre os países membros elevaria em $0,1 \%$ o nível de bem-estar da população brasileira, no caso de retornos constantes à escala, e em 0,6\%, quando se considera os efeitos de economias de escala. Harrison et al. (2003) constataram que a criação dessa área de livre comércio poderia aumentar o nível de bem-estar da economia brasileira em até 0,6\%, o que corresponderia a US\$ 3,1 bilhões.

Para Ferreira Filho e Horridge (2004), a criação da Alca, com total eliminação das tarifas de importação pelos países envolvidos, aumentaria em $0,7 \%$ o Produto Interno Bruto (PIB) real brasileiro.

Torna-se evidente que a maior abertura comercial entre as economias mundiais, no caso particular da formação da Alca, é importante para que essas possam ampliar suas relações comerciais e, assim, obter maior inserção no comércio internacional e posição mais estratégica diante dos mercados concorrentes. Contudo, para obter ganhos, os países precisam ser competitivos ante a concorrência internacional. Nesse contexto, este estudo objetivou avaliar os impactos da criação da Alca, com desgravação tarifária gradual, nos principais indicadores macroeconômicos da economia brasileira.

\section{O modelo GTAP1 e os cenários de análise}

Os modelos Computáveis de Equilíbrio Geral (CEG) descrevem, de forma simplificada, a estrutura da economia, visto que simulam o funcionamento de economias de mercado, com soluções simultâneas para preços e quantidades, e estabelecem o equilíbrio entre demanda e oferta em cada mercado analisado.

Neste trabalho, o modelo CEG utilizado é o Global Trade Analysis Project (GTAP), dada sua capacidade de analisar economias de vários países e avaliar as mudanças no comércio internacional, tornando-se, assim, um valioso instrumento para análises de integração regional. Esse modelo foi desenvolvido por Hertel e Tsigas (1997).

A base de dados a ser utilizada é a versão 6.2, que possui um banco de dados formado por 87 países e 57 setores/produtos. A agregação utilizada neste estudo é apresentada na Tabela 1. Esse banco de dados reflete o ambiente econô- 
mico de 2001 e é constituído, basicamente, pela Matriz Insumo-Produto dos países ou regiões considerados. A matriz brasileira é a de 1995, atualizada para 2001.

De acordo com Gehlhar e Hertel (1997), nem todos os países têm seus dados explicitados na base de dados do GTAP. Assim, a estratégia adotada é a elaboração de Matrizes Insumo-Produto por regiões, utilizando-se conceitos con- tábeis previamente definidos, e sendo que essas matrizes já estão incluídas no GTAP.

O GTAP, modelo de equilíbrio geral para o comércio internacional, consiste de ampla base de dados e de um modelo econômico que permite manipular e formular simulações desses dados. $\mathrm{Na}$ execução do programa GTAP, utiliza-se o software RunGTAP na versão 3.41, desenvolvido por Horridge (2005).

Tabela 1_Agregação de regiões e setores

\begin{tabular}{|c|c|}
\hline 1. Nafta & 1. Arroz de sequeiro e processado \\
\hline 2. União Européia (EU) & 2. Trigo em grão \\
\hline 3. Argentina (ARG) & 3. Milho em grão \\
\hline 4. Brasil (BRA) & 4. Soja (grão e óleo) \\
\hline 5. Uruguai (URY) & 5. Algodão \\
\hline 6. China $(\mathrm{CHN})$ & 6. Indústria do açúcar \\
\hline 7. India (IND) & 7. Carne \\
\hline 8. Resto da América (ROA) & 8. Leite e derivados \\
\hline \multirow[t]{6}{*}{ 9. Resto do Mundo (ROW) } & $\begin{array}{l}\text { 9. Oaindústria - outros produtos da agroindústria: café, suco } \\
\text { concentrado, fumo, fibras, lã, alimentos, vegetais e frutas }\end{array}$ \\
\hline & $\begin{array}{l}\text { 10. Manufaturados: máquinas e tratores, veículos, produtos } \\
\text { químicos e outros manufaturados }\end{array}$ \\
\hline & 11. Produtos florestais \\
\hline & 12. Têxteis \\
\hline & 13. Calçados de couro \\
\hline & 14. Serviços e administração pública \\
\hline
\end{tabular}

Fonte: GTAP. 
O funcionamento da economia na versão do GTAP está representado na Figura 1, que apresenta as inter-relações dos agentes no modelo.

Iniciada a descrição pela despesa do agente regional (Figura 1), nota-se que essa é dada por uma função de utilidade agregada, por meio da qual as despesas são alocadas entre consumo privado (PRIVEXP), consumo do governo
(GOVESP) e poupança global (SAVE). Já a receita do agente regional é função da venda dos serviços dos fatores primários de produção, aqui representados por VOA (valor do produto, a preços dos agentes) e pelos impostos TAXES (incididos sobre os bens domésticos), MTAX (tarifas à importação) e X'TAX (taxas à exportação).

\section{Figura 1_Economia multirregional aberta}

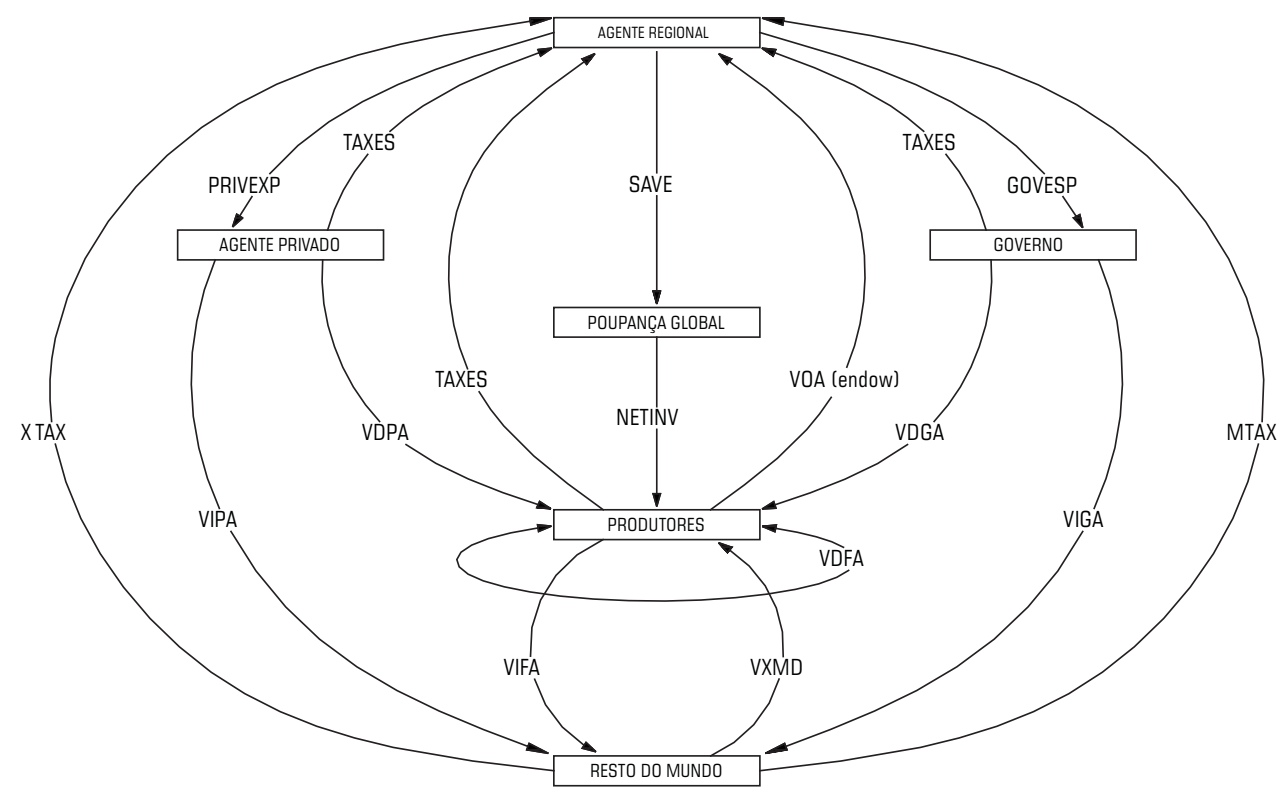

Fonte: Hertel e Tsigas (1997). 
Os produtores têm suas receitas advindas das vendas de sua produção aos agentes domésticos, que são os agentes privados $(V D P A=$ valor das compras domésticas pelo setor privado, a preços de agente), o governo (VDGA = valor das compras domésticas do governo, a preços de agente), e outras firmas (VDFA = consumo intermediário), e aos agentes externos (Resto do Mundo, que representa a fonte de importação e o destino das exportações), por meio das exportações (VXMD). Além disso, a receita pode ser gerada pelo valor das vendas de bens de investimento para satisfazer à demanda de poupanças pelos agentes regionais (REGINV).

A receita dos produtores é gasta com consumo intermediário (VDFA) na aquisição de serviços dos fatores primários (VDPA), nas importações (VIFA) e no pagamento de impostos (TAXES) ao governo. Dessa forma, toda receita gerada é despendida com a compra de fatores intermediários e serviços de fatores primários, dando, portanto, condição de lucro zero (pressuposição do fechamento).

O governo e os agentes privados gastam suas rendas em produtos domésticos e importados (VIPA, para agentes privados; VIGA, para o governo). Da mesma forma, ambos os agentes pagam impostos de importação (MTAX) e de consumo (TAXES) e poupam (SAVE). Os fluxos regionais de poupança são agregados em nível global (poupança global), que são, posteriormente, distribuídos para investimento em cada região.

As relações entre os agentes econômicos podem ser expressas em forma de valor, porém se tornam mais interessantes em forma de mudanças percentuais nos preços e nas quantidades. Os métodos de resolução matemática utilizados pelo GTAP via sistemas linearizados permitem obter, por aproximações sucessivas, resultados equivalentes aos não-lineares. O método de Gragg, que permite especificar maior número de passos, oferece solução acurada do sistema.

\subsection{Comportamento e relações econômicas dos agentes}

A Figura 2 exibe a tecnologia utilizada pelas firmas em cada indústria do modelo, que é caracterizado pela árvore tecnológica ou de produção, a qual consiste num meio eficiente de representar as tecnologias de forma separada e com retornos constantes à escala. Como o fechamento macroeconômico do GTAP é do tipo neoclássico, ele incorpora a lei dos rendimentos constantes de escala para chegar a seus resultados. 
Figura 2_Estrutura da produção

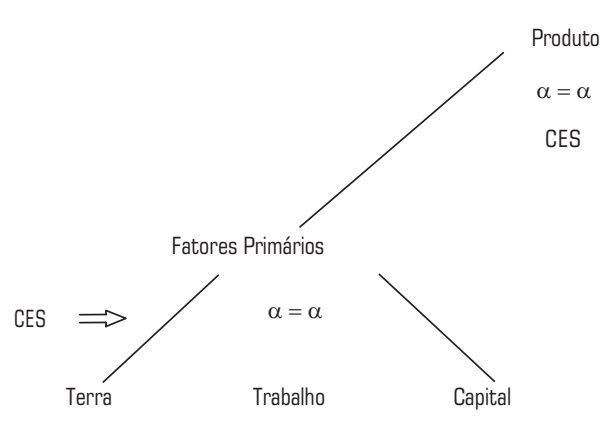

Fonte: Hertel e Tsigas (1997).

Importante observar que os efeitos de políticas comerciais em mercados com economias de escala podem ser consideravelmente diferentes daqueles observados em mercados com retornos constantes de escala. Dessa forma, a hipótese de retornos constantes de escala é uma restrição apresentada pelo GTAP.

A combinação de insumos utilizada pela firma em sua produção depende das pressuposições feitas sobre a separabilidade na produção. Assim, admite-se que as firmas escolham sua combinação ótima de fatores de produção independentemente dos preços dos insumos intermediários. Por admitir esse tipo de separabilidade, impõe-se que a elasticidade de substituição entre quaisquer dois fatores primários, de um lado, e entre quaisquer dois insumos intermediários, de outro, seja igual. Isso permite a obtenção da árvore de produção, pois, como sua elasticidade é comum, se consegue traçar o primeiro nó da árvore, na qual insumos intermediários e fatores primários são combinados. Dentro do grupo de fatores primários, as possibilidades de substituição reduzem-se a um único parâmetro, ou seja, admite-se uma função do tipo Constant Elasticity of Substitution (CES), expressa da seguinte forma:

$Q=A\left[\delta K^{-p}+(1-\delta)^{-p}\right]^{-1}$

sendo $A>0 ; \mathrm{o}<\delta<1 ; p>-1$, em que $Q$ é a quantidade produzida; $K$ (capital) e $L$ (trabalho), fatores de produção; 
$A, p$ e $\delta$, parâmetros; $A$, parâmetro que pode ser entendido como um indicador do estado de tecnologia; $\delta$, parâmetro de distribuição que se relaciona com as participações relativas dos fatores no produto; $p$, parâmetro de substituição que determina $\mathrm{O}$ valor da constante da elasticidade de substituição para funções dessa natureza.

Dessa forma, em funções do tipo CES, que possuem elasticidade de substituição constante e diferente da unidade, mudanças percentuais na relação de preços, independentemente de suas magnitudes, refletem sempre, na mesma proporção, a substitutibilidade dos bens ou fatores (Chiang, 1994). A partir da equação (1), é possível calcular a elasticidade de substituição, que será igual a

$\sigma=\frac{1}{1+p}$

Substituindo-se (2) em (1), obtémse a seguinte equação simplificada:

$Q=A\left[\delta K^{-\frac{\sigma-1}{\sigma}}+(1-\delta)^{-\frac{\sigma-1}{\sigma}}\right]^{\frac{\sigma}{\sigma-1}}$

$\mathrm{Na}$ pressuposição em que se acrescenta o fator primário terra, no caso da agricultura, requer-se apenas que todas as elasticidades de substituição entre os pares de fatores sejam iguais. $O$ fator terra é empregado apenas na atividade agrícola e é imperfeitamente móvel entre os setores, enquanto os fatores $L$ e $K$ são empregados em todos os setores e são considerados perfeitamente móveis em uma economia. A elasticidade de substituição entre os pares de fatores primários varia de atividade para atividade, mas não entre regiões. Assim, a elasticidade de substituição entre os fatores primários no agronegócio é de 0,2 nas atividades trigo, milho e algodão; 0,4 na atividade arroz; 0,5 em trigo; 0,6 para carne e leite; e 0,7 para açúcar e outras agroindústrias. Nas atividades consideradas de manufaturados, a elasticidade de substituição entre $K$ e $L$ é de 1,0 para os produtos florestais; e de 1,2 para têxteis, calçados de couro e outros manufaturados. No setor de serviços, a elasticidade de substituição entre capital $(K)$ e trabalho $(L)$ é igual a 1,4.

Os fatores intermediários também admitem a separabilidade, isto é, a combinação ótima dos fatores intermediários também independe do preço dos fatores primários. Assume-se que a elasticidade parcial de substituição entre os fatores intermediários seja constante e igual a zero, isto é, a combinação entre eles ocorre em proporção fixa. Além disso, admite-se a separabilidade entre insumos domésticos e importados, ou seja, as firmas decidem a fonte de suas importações e, baseadas nos preços de importação, determinam a combinação ótima de insumos domésticos e importados. A elastici- 
dade parcial de substituição entre fatores domésticos e importados para a atividade arroz é de 3,8; para trigo, 4,4; para milho, 1,3; para soja, 3,0; para algodão, 2,5; para açúcar, 2,7; para carne, 2,9; para leite, 3,7; para outras agroindústrias, 1,9; para produtos florestais, 3,2; para têxteis e calçados de couro, 3,8; para outros manufaturados, 3,5; e para serviços, 1,9. Essa especificação foi formulada por Paul Armington em 1969 e, desde então, tem sido conhecida como formulação de Armington para modelagem da demanda de importação. Assim, o comércio internacional equilibra o mercado de produtos, sendo cada um desses diferenciado pela sua origem (neste caso, a pressuposição de Armington é aplicada ao país).

Ao direcionar a análise para o comportamento dos indivíduos, verifica-se, conforme já mencionado, que o consumo regional é governado por uma função de utilidade agregada que depende do consumo privado (CP), das despesas do governo (CG) e da poupança (S). Dessa forma, a renda regional é distribuída de acordo com uma função de utilidade per capita Cobb-Douglas, definida por três formas de demanda final - consumo privado, consumo do governo e poupança, conforme equação (4).

$U=K C P^{\theta C P} C G^{\theta C G} S^{\theta S}$ em que $U$ é utilidade total em cada região $K$, e $\theta$, parâmetros da função. A maximização da função utilidade determina a alocação da renda em cada região, entre as três formas de demanda. Como a função de utilidade é uma Cobb-Douglas, o fechamento padrão do GTAP faz com que a participação de cada um daqueles itens da demanda final na renda total seja constante.

\subsection{Fechamento macroeconômico do modelo e alocação do investimento entre regióes}

Assim como muitos modelos aplicados de equilíbrio geral, o GTAP não considera as políticas macroeconômicas e os fenômenos monetários que, normalmente, são fatores explicativos do investimento agregado. Ademais, por não ser um modelo intertemporal (dinâmico) ou seqüenciado no tempo, o que permitiria a obtenção de séries de equilíbrio no tempo, o investimento não é capaz, no modelo, de afetar a capacidade produtiva das indústrias/regiões. A alocação de investimentos entre as regiões afeta a produção e o comércio apenas por meio dos efeitos sobre a demanda final. Essas observações justificam a maior atenção dada a essa questão, além de o tratamento entre poupança e investimento ser necessário para completar 
o sistema econômico global, assegurando consistência no sistema de contas.

Além do fechamento, com relação ao investimento, é necessário lidar com mudanças potenciais na conta-corrente. Geralmente, os procedimentos de fechamento forçam a convergência entre poupança e investimento doméstico, fixando o balanço da conta-corrente, que pode ser expresso pela fixação do lado esquerdo da identidade das contas nacionais, como segue:

$S-I \equiv X+R-M$

em que $S$ é poupança; $I$, investimento; $X$, exportações; $M$, importações; $R$, transferências internacionais.

Ao fixar, regionalmente, o lado direito da identidade citada, cada região no mercado global passará a ter uma quota fixa de poupança líquida; assim, será assegurada a igualdade entre poupança e investimento global, mesmo sem presença de um banco global para fazer a intermediação entre esse tipo de poupança e investimento global. Essa abordagem representa um fechamento de equilíbrio neoclássico, uma vez que o investimento é forçado a se alinhar às mudanças regionais da poupança.

Entretanto, alguns experimentos requerem a exogeneidade de ambos os lados da identidade. Assim, necessita-se de um mecanismo que assegure a igualdade entre as demandas globais de poupança e investimento, que, no caso do GTAP, referem-se ao "banco global". Dessa forma, o fechamento global também será neoclássico.

Por fim, como os modelos aplicados de equilíbrio geral são fundamentados no modelo walrasiano de equilíbrio geral, em que os preços são relativos, é necessário escolher um bem como numerário, em relação ao qual todos os preços do modelo serão expressos. No modelo GTAP, o numerário é o preço internacional dos serviços dos fatores primários.

\section{3_Cenários de análise}

Com o intuito de ter uma visão mais realista do cenário Mercosul após as agregações de países e setores, promoveram-se algumas mudanças na base tarifária do GTAP. Nesse caso, eliminaram-se todas as tarifas de importação entre os membros do Mercosul, exceto as do açúcar e dos manufaturados que continuam com tarifas de importação entre os membros do bloco e padronizaram-se as tarifas para os demais países, de acordo com a Tarifa Externa Comum do Mercosul (TEC), conforme Tabela 2 . 
Tabela 2_ Tarifa Externa Comum para o Mercosul, 2005

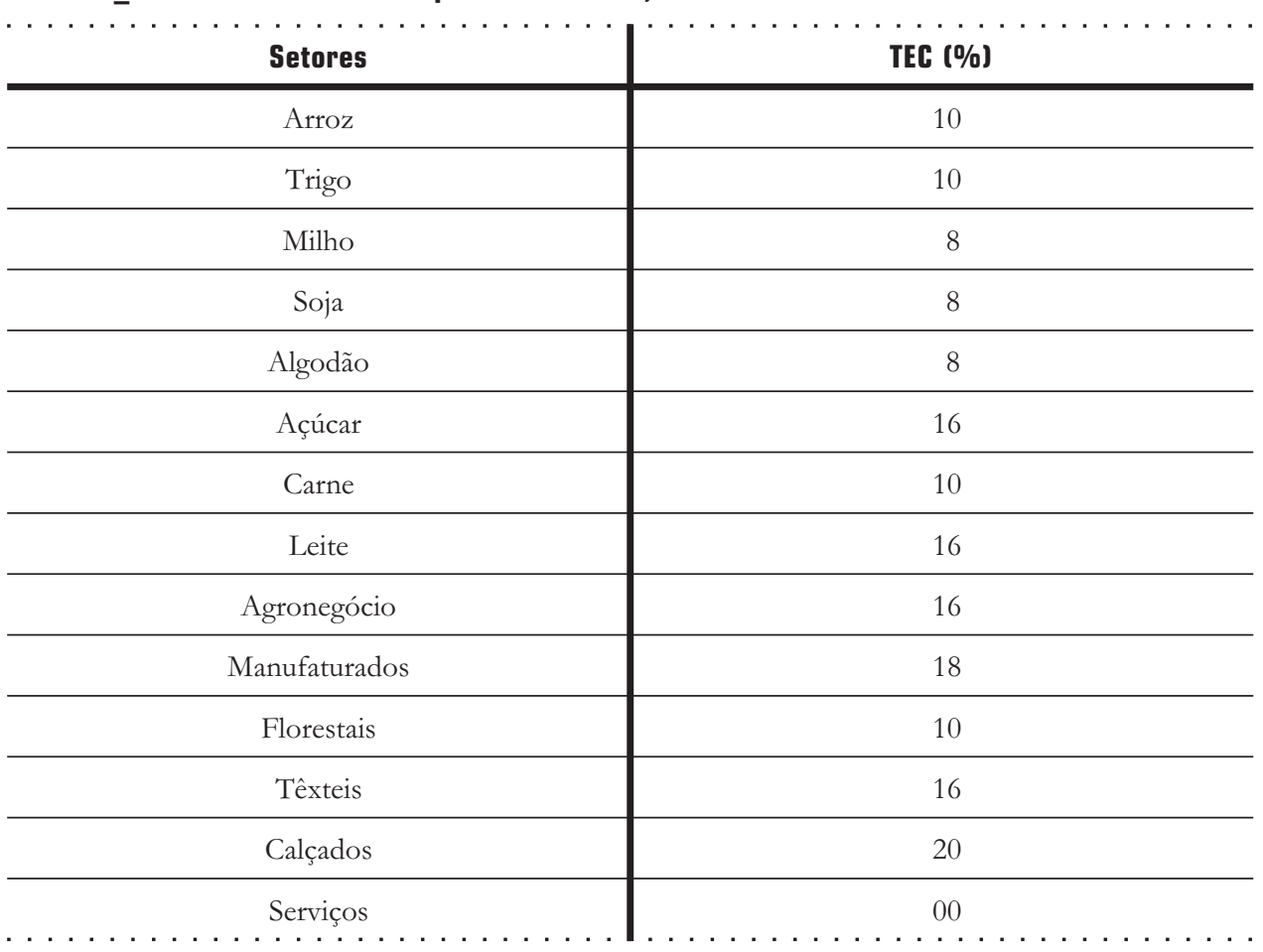

Fonte: Ministério do Desenvolvimento, Indústria e Comércio - MDIC (2005).

Foram definidas quatro fases para efeito de desgravação tarifária na Alca (Tabela 3): primeira fase, imediata; segunda fase, até cinco anos; terceira fase, até 10 anos; e quarta fase, acima de 10 anos, ou seja, sem prazo definido. Para atender aos objetivos deste trabalho, fo- ram criados quatro cenários de análise; nos cenários I, II e III, as ofertas iniciais são propostas pelo Mercosul e pelos EUA, e no cenário IV, as ofertas eliminam, totalmente, as tarifas de importação entre os membros da Alca. Os cenários são descritos a seguir. 
Tabela 3 Perfil das ofertas tarifárias propostas pelos EUA e Mercosul para a Alca, em percentuais

\begin{tabular}{|c|c|c|c|c|}
\hline \multirow{2}{*}{ Cestas } & \multicolumn{2}{|c|}{ Agrícola } & \multicolumn{2}{|c|}{ Não-Agrícola } \\
\hline & EUA & Mercosul & EUA & Mercosul \\
\hline A & 35,6 & 11,9 & 51,7 & 18,0 \\
\hline B & 17,9 & 16,0 & 26,1 & 3,6 \\
\hline $\mathrm{C}$ & 14,6 & 41,0 & 22,2 & 28,1 \\
\hline $\mathrm{D}$ & 31,9 & 31,1 & 0,0 & 50,3 \\
\hline
\end{tabular}

Fonte: Beraldo (2004).

Nota: Categorias de desgravação: A - imediata; B - até 5 anos; C - até 10 anos; e D - acima de 10 anos.

Cenário I: primeira fase, imediata. A oferta dos Estados Unidos visa à eliminação de 35,6\% das tarifas sobre os bens agrícolas e de $51,7 \%$ sobre os não-agrícolas. O Mercosul sugere eliminação de $11,9 \%$ das tarifas sobre os bens agrícolas e de $18,0 \%$ sobre os nãoagrícolas.

_ Cenário II: segunda fase, até cinco anos. A proposta dos Estados Unidos é que, em até cinco anos, sejam eliminadas 53,5\% das tarifas de importação sobre os bens agrícolas e 77,8\% para os nãoagrícolas. O Mercosul sugere que, em cinco anos, estejam eliminadas $27,9 \%$ das tarifas sobre os bens agrícolas e $21,6 \%$ sobre os não-agrícolas.
Cenário III: terceira fase, até 10 anos. Os Estados Unidos sugerem a eliminação de 68,1\% das tarifas de importação sobre os bens agrícolas e de 100,0\% sobre os não-agrícolas, em até 10 anos. Quanto à oferta do Mercosul, essa pretende que, em até 10 anos, sejam eliminadas 68,9\% das tarifas de importação sobre bens agrícolas e 49,7\% das tarifas sobre os não-agrícolas.

_ Cenário IV: quarta fase, acima de 10 anos. Ambas as ofertas, a dos Estados Unidos e a do Mercosul, sugerem a eliminação de 100,0\% das tarifas de importação tanto sobre os bens agrícolas quanto sobre os não-agrícolas, porém sem prazo definido. 


\section{Resultados e discussões}

Nesta seção, é feita uma análise conjunta dos resultados encontrados após as simulações dos cenários I, II, III e IV, avaliando-se as diferenças entre as ofertas iniciais dos Mercosul e dos EUA. Em razão dos objetivos propostos, dar-se-á maior ênfase aos resultados encontrados para o Brasil e ao cenário IV.

\section{1_ Impactos na economia brasileira advindos da criação da Alca, com gradual desgravação tarifária}

A Tabela 4 apresenta a variação percentual na quantidade produzida dos diferentes produtos pelo Brasil. Nota-se que, nos cenários I, II e III, em que são comparadas as ofertas de tarifas do Mercosul (OMS) com a dos EUA (OEUA), a produção da maioria dos produtos do agronegócio diminuiu, com impacto mais significativo na proposta dos EUA. Isso decorre, em parte, porque as TECs do Mercosul são elevadas em relação às de outros países membros da Alca, em vários cenários e produtos, além de a redução dessas tarifas ter promovido pequenas quedas na produção, a maior de $1,65 \%$ para a soja, no cenário em que ocorreu eliminação completa das tarifas. Também contribuiu para essa pequena queda de produção o fato de os EUA subsidiarem a produção de produtos como soja, algodão e milho. Assim, permanecem as distorções comerciais que reduzem os ganhos brasileiros em produção no agronegócio, mesmo com eliminação de tarifas de importação.

Para produtos florestais, têxteis e calçados, ocorreu aumento na produção, nos cenários I, II e III, com destaque para as ofertas dos EUA, que causaram mudanças mais expressivas, como o crescimento de $14,07 \%$ na produção de calçados, no cenário III. A produção desses produtos não é subsidiada pelos EUA.

Para o agregado Oaindústria, ou seja, outros produtos do agronegócio, como café, fumo, suco de laranja, produtos processados, bebidas, houve ganhos de produção em todos os cenários analisados, principalmente no cenário IV, com elevação de $1,39 \%$ na quantidade produzida. No setor de manufaturados, houve redução na produção, em todos os cenários, o que revela sua baixa competitividade em relação ao mercado internacional, devido, em parte, aos elevados custos com encargos trabalhistas, deficiências na infra-estrutura de comercialização e burocracia, alta carga tributária brasileira, mais de 35\% PIB, e elevada taxa de juros real. Vale notar que os efeitos positivos e negativos na produção se avolumaram com os choques de liberalização até atingir a liberalização total, isto é, eliminação de 100,0\% das tarifas. 
Tabela 4_Variação percentual na quantidade produzida (qo) pelo Brasil, nos diferentes cenários

\begin{tabular}{|c|c|c|c|c|c|c|c|}
\hline & \multicolumn{2}{|c|}{ Cenário I } & \multicolumn{2}{|c|}{ Cenário II } & \multicolumn{2}{|c|}{ Cenário III } & \multirow{2}{*}{$\frac{\text { Cenário IV }}{\text { LTotal }}$} \\
\hline & OMS & OEUA & OMS & OEUA & OMS & OEUA & \\
\hline Arroz & 0,03 & 0,07 & 0,16 & 0,17 & 0,51 & 0,22 & 0,75 \\
\hline Trigo & $-0,10$ & $-1,25$ & 0,13 & $-0,09$ & 0,69 & 0,05 & 1,30 \\
\hline Milho & $-0,13$ & $-0,36$ & $-0,11$ & $-0,41$ & $-0,16$ & $-0,46$ & $-0,24$ \\
\hline Soja & $-0,37$ & $-1,08$ & $-0,47$ & $-1,31$ & $-1,02$ & $-1,54$ & $-1,65$ \\
\hline Algodão & $-0,21$ & $-0,55$ & $-0,27$ & $-0,42$ & $-0,52$ & $-0,25$ & $-0,39$ \\
\hline Açúcar & $-0,33$ & $-0,87$ & $-0,40$ & $-1,15$ & $-0,92$ & $-1,33$ & $-1,48$ \\
\hline Carne & $-0,17$ & $-0,47$ & $-0,20$ & $-0,62$ & $-0,46$ & $-0,76$ & $-0,79$ \\
\hline Leite & 0,02 & $-0,01$ & 0,05 & $-0,03$ & 0,11 & $-0,12$ & 0,01 \\
\hline Oaindústria & 0,06 & 0,22 & 0,26 & 0,41 & 0,85 & 0,60 & 1,39 \\
\hline Manufaturados & $-0,38$ & $-1,06$ & $-0,53$ & $-1,65$ & $-1,31$ & $-2,06$ & $-2,36$ \\
\hline Florestais & 0,01 & 0,04 & 0,01 & 0,15 & 0,06 & 0,24 & 0,23 \\
\hline Têxteis & 0,30 & 0,90 & 0,34 & 1,75 & 0,88 & 2,54 & 2,43 \\
\hline Calçados & 1,81 & 5,66 & 2,03 & 10,01 & 5,04 & 14,07 & 13,33 \\
\hline Serviços & 0,07 & 0,18 & 0,08 & 0,25 & 0,17 & 0,29 & 0,28 \\
\hline
\end{tabular}

Fonte: Elaborado a partir dos resultados da pesquisa.

Nota: OMS = Oferta do Mercosul; OEUA = Oferta dos EUA; LTotal = liberalização total (redução de $100 \%$ nas tarifas de importação) 
A Tabela 5 demonstra as variações nas exportações do Brasil após as simulações. No agronegócio, as exportações de quase todos os produtos diminuíram, dada a queda na quantidade produzida, com exceção do arroz e leite; porém, como o Brasil quase não os exporta, esse aumento é irrelevante. Para o Oaindústria, produtos de grande importância na pauta de exportações brasileiras, houve uma elevação expressiva que chegou a $11,02 \%$ no cenário IV. Quanto aos manufaturados, os cenários liberalizantes tiveram efeito gradual e expressivo no aumento das exportações. Como o Brasil elevou a produção de produtos, como florestais, têxteis e calçados, as exportações elevaram-se bastante, com acréscimo de $40,16 \%$ para têxteis, no cenário IV. Ressalta-se que, enquanto as quedas nas exportações foram pequenas, os aumentos foram grandes e maiores para as ofertas americanas e nos cenários mais liberalizantes.

A Tabela 6 representa a evolução das importações brasileiras. Nota-se que, nos cenários I e II, ocorreu maior elevação na quantidade importada dos diferentes produtos quando consideradas as ofertas dos EUA. Já no cenário III, a importação de produtos, como trigo, milho, soja e açúcar, aumentou de forma mais acentuada na oferta do Mercosul; porém não foram significativas, dado que o Bra- sil importa muito pouco desses produtos do agronegócio, com exceção do trigo. Destaca-se que a importação de produtos não-agrícolas aumentou significativamente, a exemplo de manufaturados, que chegou a crescer $23,53 \%$, no cenário IV. Esse grande aumento nas importações brasileiras deveu-se a dois motivos: aumento nos preços domésticos e redução no preço das importações (Tabelas 7 e 8).

Destaca-se que o aumento das importações de manufaturados foi maior que o das exportações, o que pode implicar déficit na balança comercial. Para os outros produtos, Oagroindústria, florestais, têxteis e calçados, os aumentos nas importações, que foram pequenos, foram menores que os acréscimos nas exportações, que foram grandes, com exceção dos produtos florestais, cujo aumento nas importações foi maior que nas exportações.

O aumento nos preços domésticos, após reduções tarifárias, pode ser observado na Tabela 7. Nota-se que as ofertas tarifárias do Mercosul e dos EUA elevaram praticamente todos os preços internos, nos cenários I, II e III, exceto para manufaturados, cujo preço foi reduzido. As maiores elevações nos preços foram para as ofertas dos EUA. No cenário IV, eliminação total das tarifas, ocorreu o mesmo, ou seja, apenas no setor de manufaturados houve redução no preço interno, neste caso, de $0,62 \%$. 
Tabela 5_Variação percentual na quantidade exportada (qxw) pelo Brasil, conforme cenários

\begin{tabular}{|c|c|c|c|c|c|c|c|}
\hline & \multicolumn{2}{|c|}{ Cenário I } & \multicolumn{2}{|c|}{ Cenário II } & \multicolumn{2}{|c|}{ Cenário III } & \multirow{2}{*}{$\frac{\text { Cenário II }}{\text { LT }}$} \\
\hline & OMS & OEUA & OMS & OEUA & OMS & OEUA & \\
\hline Arroz & 2,34 & 7,91 & 7,01 & 13,85 & 21,02 & 19,30 & 34,22 \\
\hline Trigo & $-3,26$ & $-8,34$ & $-6,54$ & $-12,40$ & $-14,80$ & $-14,86$ & $-20,22$ \\
\hline Milho & $-0,41$ & $-1,16$ & $-0,59$ & $-1,49$ & $-1,32$ & $-1,74$ & $-2,01$ \\
\hline Soja & $-0,75$ & $-2,17$ & $-0,91$ & $-2,53$ & $-1,95$ & $-2,87$ & $-3,08$ \\
\hline Algodão & $-0,46$ & $-1,11$ & $-0,09$ & $-1,34$ & 0,24 & $-1,44$ & $-0,25$ \\
\hline Açúcar & $-0,55$ & $-1,43$ & $-0,63$ & $-1,69$ & $-1,40$ & $-1,80$ & $-2,03$ \\
\hline Carne & $-1,19$ & $-3,21$ & $-1,33$ & $-4,26$ & $-2,90$ & $-5,03$ & $-4,93$ \\
\hline Leite & 0,85 & 3,21 & 3,97 & 7,98 & 15,19 & 12,45 & 28,82 \\
\hline Oaindústria & 0,40 & 1,72 & 1,92 & 3,42 & 6,40 & 5,16 & 11,02 \\
\hline Manufaturados & 2,67 & 8,04 & 3,03 & 15,03 & 7,72 & 21,54 & 20,60 \\
\hline Florestais & 0,36 & 1,13 & 0,24 & 2,81 & 0,72 & 4,34 & 3,56 \\
\hline Têxteis & 4,84 & 15,56 & 5,76 & 28,11 & 14,99 & 40,80 & 40,16 \\
\hline Calçados & 2,94 & 9,36 & 3,31 & 16,44 & 8,29 & 23,21 & 22,06 \\
\hline Serviços & $-0,97$ & $-2,61$ & $-1,29$ & $-3,65$ & $-2,89$ & $-4,40$ & $-4,80$ \\
\hline
\end{tabular}

Fonte: Elaborado a partir dos resultados da pesquisa.

Nota: OMS = Oferta do Mercosul; OEUA = Oferta dos EUA; LTotal = liberalização total (redução de $100 \%$ nas tarifas de importação). 
Tabela 6_Variação percentual na quantidade importada (qiw) pelo Brasil, em diferentes cenários

\begin{tabular}{|c|c|c|c|c|c|c|c|}
\hline & \multicolumn{2}{|c|}{ Cenário I } & \multicolumn{2}{|c|}{ Cenário II } & \multicolumn{2}{|c|}{ Cenário III } & \multirow{2}{*}{$\frac{\text { Cenário IV }}{\text { LTotal }}$} \\
\hline & OMS & OEUA & OMS & OEUA & OMS & OEUA & \\
\hline Arroz & 0,45 & 1,94 & 0,30 & 1,71 & 0,37 & 2,08 & 0,76 \\
\hline Trigo & 0,03 & 0,40 & 0,16 & 0,28 & 0,57 & 0,41 & 0,97 \\
\hline Milho & 0,19 & 0,94 & 0,52 & 0,96 & 1,41 & 1,26 & 2,06 \\
\hline Soja & 1,54 & 5,07 & 3,60 & 7,31 & 9,76 & 9,50 & 14,95 \\
\hline Algodão & 1,16 & 3,68 & 2,18 & 5,72 & 5,70 & 7,67 & 9,99 \\
\hline Açúcar & 3,67 & 12,21 & 8,91 & 18,56 & 25,28 & 24,64 & 40,68 \\
\hline Carne & 1,34 & 4,43 & 2,77 & 6,32 & 7,59 & 8,18 & 12,32 \\
\hline Leite & 0,66 & 3,16 & 0,89 & 2,79 & 2,27 & 3,51 & 4,12 \\
\hline Oaindústria & 1,08 & 3,68 & 2,32 & 5,19 & 6,51 & 6,78 & 10,69 \\
\hline Manufaturados & 2,90 & 8,80 & 3,57 & 16,43 & 9,34 & 23,41 & 23,53 \\
\hline Florestais & 2,15 & 6,60 & 2,70 & 10,27 & 6,60 & 13,71 & 14,12 \\
\hline Têxteis & 1,97 & 6,90 & 2,46 & 11,12 & 6,38 & 16,04 & 16,22 \\
\hline Calçados & 2,04 & 7,91 & 2,42 & 12,16 & 6,35 & 18,13 & 17,78 \\
\hline Serviços & 0,52 & 1,42 & 0,69 & 1,97 & 1,57 & 2,34 & 2,56 \\
\hline
\end{tabular}

Fonte: Elaborado a partir dos resultados da pesquisa.

Nota: OMS = Oferta do Mercosul; OEUA = Oferta dos EUA; LTotal = liberalização total (redução de 100\% nas tarifas de importação). 
Tabela 7 Variação percentual nos preços domésticos (pm) brasileiros nos diferentes cenários

\begin{tabular}{|c|c|c|c|c|c|c|c|}
\hline & \multicolumn{2}{|c|}{ Cenário I } & \multicolumn{2}{|c|}{ Cenário II } & \multicolumn{2}{|c|}{ Cenário III } & \multirow{2}{*}{$\frac{\text { Cenário II }}{\text { Ltotal }}$} \\
\hline & OMS & OEUA & OMS & OEUA & OMS & OEUA & \\
\hline Arroz & 0,23 & 0,61 & 0,33 & 0,85 & 0,76 & 1,01 & 1,21 \\
\hline Trigo & 0,17 & 0,33 & 0,27 & 0,58 & 0,65 & 0,66 & 0,95 \\
\hline Milho & 0,19 & 0,51 & 0,28 & 0,69 & 0,66 & 0,81 & 1,01 \\
\hline Soja & 0,16 & 0,42 & 0,23 & 0,53 & 0,50 & 0,59 & 0,71 \\
\hline Algodão & 0,21 & 0,56 & 0,30 & 0,80 & 0,71 & 0,98 & 1,16 \\
\hline Açúcar & 0,16 & 0,42 & 0,23 & 0,50 & 0,50 & 0,53 & 0,66 \\
\hline Carne & 0,23 & 0,62 & 0,32 & 0,86 & 0,73 & 1,03 & 1,18 \\
\hline Leite & 0,24 & 0,65 & 0,33 & 0,90 & 0,77 & 1,08 & 1,25 \\
\hline Oaindústria & 0,22 & 0,59 & 0,31 & 0,81 & 0,71 & 0,96 & 1,13 \\
\hline Manufaturados & $-0,01$ & $-0,08$ & 0,01 & $-0,41$ & $-0,05$ & $-0,72$ & $-0,62$ \\
\hline Florestais & 0,21 & 0,58 & 0,29 & 0,76 & 0,66 & 0,88 & 1,01 \\
\hline Têxteis & 0,10 & 0,21 & 0,14 & 0,15 & 0,27 & 0,04 & 0,13 \\
\hline Calçados & 0,13 & 0,33 & 0,19 & 0,33 & 0,40 & 0,29 & 0,40 \\
\hline Serviços & 0,25 & 0,69 & 0,34 & 0,96 & 0,77 & 1,15 & 1,28 \\
\hline
\end{tabular}

Fonte: Elaborado a partir dos resultados da pesquisa.

Nota: OMS = Oferta do Mercosul; OEUA = Oferta dos EUA; LTotal = liberalização total (redução de $100 \%$ nas tarifas de importação). 
Tabela 8_ Variação percentual nos preços das importações (pim) brasileiras, nos diferentes cenários

\begin{tabular}{|c|c|c|c|c|c|c|c|}
\hline & \multicolumn{2}{|c|}{ Cenário I } & \multicolumn{2}{|c|}{ Cenário II } & \multicolumn{2}{|c|}{ Cenário III } & \multirow{2}{*}{$\begin{array}{c}\text { Cenário IV } \\
\text { LT }\end{array}$} \\
\hline & OMS & OEUA & OMS & OEUA & OMS & OEUA & \\
\hline Arroz & 0,11 & 0,10 & 0,27 & 0,41 & 0,76 & 0,48 & 1,15 \\
\hline Trigo & 0,13 & $-0,08$ & 0,24 & 0,46 & 0,63 & 0,53 & 0,96 \\
\hline Milho & $-0,08$ & $-0,58$ & $-0,26$ & $-0,45$ & $-0,64$ & $-0,60$ & $-0,81$ \\
\hline Soja & $-0,45$ & $-1,52$ & $-1,10$ & $-2,18$ & $-2,88$ & $-2,85$ & $-4,30$ \\
\hline Algodão & $-0,28$ & $-0,96$ & $-0,73$ & $-1,35$ & $-1,88$ & $-1,76$ & $-2,74$ \\
\hline Açúcar & $-1,22$ & $-3,87$ & $-2,93$ & $-5,74$ & $-7,53$ & $-7,43$ & $-11,23$ \\
\hline Carne & $-0,27$ & $-0,96$ & $-0,69$ & $-1,38$ & $-1,88$ & $-1,84$ & $-2,90$ \\
\hline Leite & 0,03 & $-0,27$ & 0,02 & $-0,01$ & 0,00 & $-0,08$ & $-0,10$ \\
\hline Oaindústria & $-0,40$ & $-1,41$ & $-0,98$ & $-2,00$ & $-2,66$ & $-2,65$ & $-4,16$ \\
\hline Manufaturados & $-1,12$ & $-3,25$ & $-1,35$ & $-5,82$ & $-3,40$ & $-7,99$ & $-7,98$ \\
\hline Florestais & $-0,47$ & $-1,44$ & $-0,56$ & $-2,29$ & $-1,38$ & $-3,08$ & $-3,07$ \\
\hline Têxteis & $-0,43$ & $-1,53$ & $-0,52$ & $-2,48$ & $-1,37$ & $-3,53$ & $-3,51$ \\
\hline Calçados & $-0,23$ & $-1,07$ & $-0,26$ & $-1,60$ & $-0,75$ & $-2,47$ & $-2,39$ \\
\hline Serviços & $-0,02$ & $-0,05$ & $-0,02$ & $-0,09$ & $-0,06$ & $-0,12$ & $-0,12$ \\
\hline
\end{tabular}

Fonte: Elaborado a partir dos resultados da pesquisa.

Nota: OMS = Oferta do Mercosul; OEUA = Oferta dos EUA; LTotal = liberalização total (redução de $100 \%$ nas tarifas de importação). 
No que se refere aos preços das importações brasileiras (Tabela 8), houve queda no preço de quase todos os produtos comercializados. Nos cenários I e II, as ofertas dos EUA tiveram maior impacto na redução dos preços. No cenário III, a oferta do Mercosul reduziu mais os preços dos produtos do agronegócio, destacando-se a queda de 7,53\% no preço do açúcar, enquanto o preço dos produtos não-agrícolas caiu de maneira mais acentuada, para a oferta dos EUA. No cenário IV, houve aumento apenas nos preços do arroz e do trigo, enquanto ocorreu queda nos preços dos outros produtos, $11,23 \%$ para açúcar e $7,98 \%$ para manufaturados.

A Tabela 9 resume os resultados das variações nos termos de troca, decorrentes das variações nos preços internacionais recebidos e pagos pelo Brasil. É importante ressaltar que termos de troca são, por definição, a razão entre os preços internacionais e os preços domésticos; no entanto, o GTAP traz índices de preços, isto é, já está inclusa a razão entre os preços. Em todos os cenários ocorreu elevação nos termos de troca da economia brasileira; nos cenários I e II, houve maior aumento nos termos de troca brasileiro para as ofertas dos EUA, enquanto, no cenário III, os maiores ganhos foram para a oferta do Mercosul, cerca de 0,29\%. Com redução total das tarifas (ce- nário IV), o ganho nos termos de troca foi de $0,14 \%$.

Dadas as variações nas exportações e importações brasileiras, a Tabela 10 apresenta as mudanças que podem ocorrer na balança comercial (exportações importações) do Brasil. No geral, como as importações brasileiras dos diferentes setores aumentaram mais do que as exportações, especialmente de manufaturados, a balança comercial do País foi deficitária em todos os cenários de ofertas. O maior déficit apareceu no cenário IV, cerca de US\$ 5017,8 milhões.

$\mathrm{Na}$ Tabela 11 são observadas as variações no PIB, na utilidade per capita (U) e na variação equivalente (VE) das diferentes regiões. De acordo com Varian (1993), a utilidade indica o nível de satisfação de cada bem ou serviço consumido durante certo período de tempo. No modelo GTAP, a utilidade é representada pelo consumo privado e do governo e pela poupança; portanto, as variações na utilidade estão explicitadas de forma agregada e per capita. A variação equivalente é uma medida de bem-estar que mede, em termos monetários, o impacto de uma variação de preço na utilidade do consumidor, ou seja, consiste em perguntar quanto dinheiro teria de se dar ao consumidor antes da redução de preço, para lhe deixar tão bem quanto estaria depois da variação de preço. 
Tabela 9_ Variação percentual nos preços recebidos (psw), nos preços pagos (pdw) e nos termos de troca (tot $=$ psw $-p d w$ ) do Brasil, em diferentes cenários

\begin{tabular}{|c|c|c|c|c|c|c|c|}
\hline & \multicolumn{2}{|c|}{ Cenário I } & \multicolumn{2}{|c|}{ Cenário II } & \multicolumn{2}{|c|}{ Cenário III } & \multirow{2}{*}{$\frac{\text { Cenário IV }}{\text { LT }}$} \\
\hline & OMS & OEUA & OMS & OEUA & OMS & OEUA & \\
\hline$p s w$ & 0,09 & 0,2 & 0,14 & 0,1 & 0,26 & $-0,04$ & 0,08 \\
\hline$p d w$ & $-0,01$ & $-0,08$ & $-0,01$ & $-0,06$ & $-0,02$ & $-0,08$ & $-0,06$ \\
\hline tot & 0,1 & 0,28 & 0,15 & 0,16 & 0,29 & 0,04 & 0,14 \\
\hline
\end{tabular}

Fonte: Elaborado a partir dos resultados da pesquisa.

Nota: OMS = Oferta do Mercosul; OEUA = Oferta dos EUA; LTotal = liberalização total (redução de 100\% nas tarifas de importação).

Tabela 10_ Variações na balança comercial (dthal), em milhões de dólares, nos diferentes cenários

\begin{tabular}{|c|c|c|c|c|c|c|c|}
\hline & \multicolumn{2}{|c|}{ Cenário I } & \multicolumn{2}{|c|}{ Cenário II } & \multicolumn{2}{|c|}{ Cenário III } & \multirow{2}{*}{$\frac{\text { Cenário IV }}{\text { LT }}$} \\
\hline & OMS & OEUA & OMS & OEUA & OMS & OEUA & \\
\hline Nafta & $-9,90$ & $-126,58$ & $-48,02$ & $-20,85$ & $-118,36$ & 0,96 & $-78,15$ \\
\hline $\mathrm{EU}$ & 608,43 & 1851,63 & 796,64 & 3046,82 & 1996,52 & 4128,50 & 4322,72 \\
\hline ARG & $-117,17$ & $-297,54$ & $-145,30$ & $-626,95$ & $-370,39$ & $-874,21$ & $-887,66$ \\
\hline BRA & $-692,89$ & $-2026,52$ & $-870,49$ & $-3571,52$ & $-2198,37$ & $-4902,12$ & $-5017,80$ \\
\hline URY & $-10,99$ & $-36,32$ & $-13,20$ & $-56,90$ & $-41,98$ & $-77,88$ & $-89,59$ \\
\hline $\mathrm{CHN}$ & 70,72 & 207,56 & 85,38 & 351,06 & 212,36 & 475,35 & 482,42 \\
\hline IND & 22,65 & 67,39 & 27,92 & 113,57 & 69,82 & 154,31 & 157,90 \\
\hline $\mathrm{ROA}$ & $-553,31$ & $-1698,64$ & $-701,32$ & $-2642,40$ & $-1715,97$ & $-3524,38$ & $-3666,54$ \\
\hline ROW & 682,47 & 2059,03 & 868,39 & 3407,18 & 2166,37 & 4619,47 & 4776,69 \\
\hline
\end{tabular}

Fonte: Elaborado a partir dos resultados da pesquisa.

Nota: OMS = Oferta do Mercosul; OEUA = Oferta dos EUA; LTotal = liberalização total (redução de $100 \%$ nas tarifas de importação) . 
Tabela 11_Variações percentuais no Produto Interno Bruto (PIB) e utilidade "per capita" (U), e variação equivalente (VE), em milhões de dólares, no Brasil, nos diferentes cenários

\begin{tabular}{|c|c|c|c|c|c|c|c|}
\hline & \multicolumn{2}{|c|}{ Cenário I } & \multicolumn{2}{|c|}{ Cenário II } & \multicolumn{2}{|c|}{ Cenário III } & Cenário IV \\
\hline & OMS & OEUA & OMS & OEUA & OMS & OEUA & LT \\
\hline PIB & 0,2 & 0,49 & 0,27 & 0,44 & 0,54 & 0,31 & 0,43 \\
\hline $\mathrm{U}$ & 0,08 & 0,19 & 0,10 & 0,15 & 0,19 & 0,06 & 0,08 \\
\hline VE & 368,64 & 861,86 & 465,08 & 666,08 & 838,98 & 245,89 & 332,82 \\
\hline
\end{tabular}

Fonte: Elaborado a partir dos resultados da pesquisa.

Nota: OMS = Oferta do Mercosul; OEUA = Oferta dos EUA; LTotal = liberalização total (redução de $100 \%$ nas tarifas de importação)

Verifica-se, na economia brasileira, que o PIB aumentou em ambos os cenários analisados. Nos cenários I e II, os ganhos com as ofertas tarifárias dos EUA foram maiores do que os da oferta do Mercosul. No cenário III, a oferta dessa área de livre comércio provocou elevação de $0,54 \%$ no PIB brasileiro, enquanto a oferta dos EUA causou aumento de $0,31 \%$. Com liberalização total (cenário IV), houve aumento de $0,43 \%$ no PIB do Brasil.

No que se refere à satisfação dos agentes econômicos, nota-se na Tabela 11 que as ofertas dos EUA, nos cenários I e II, geraram maior satisfação aos agentes econômicos brasileiros do que a do Mercosul. Entretanto, no cenário III, a oferta deste gerou aumento de bem-estar maior que a dos EUA, o que elevou a utilidade dos agentes econômicos em 0,19\%. É importante ressaltar que o aumento de utilidade, no cenário IV (liberalização total), foi menor do que as variações constatadas; por exemplo, no cenário I, para oferta dos EUA (0,19\%), e no canário III, para a oferta do Mercosul $(0,19 \%)$. Nesse caso, a liberalização total da economia brasileira causaria menores impactos de bem-estar nos consumidores do que nos cenários de menor abertura comercial.

Os ganhos dos agentes econômicos também podem ser visualizados, em termos de variação equivalente, na Tabela 11 . Observa-se que o maior ganho dos agentes econômicos brasileiros foi no cenário I, com a oferta dos EUA, em que a renda agregada teve crescimento de US\$ 861,86 milhões. No cenário II, a oferta dos EUA também foi melhor para o Brasil, enquanto 
no cenário III, a oferta do Mercosul promoveu maiores ganhos de renda agregada. O aumento de US\$332,82 milhões na renda dos agentes econômicos brasileiros, com liberalização total (cenário IV), foi inferior a praticamente todos os ganhos verificados nos cenários I, II e III, exceto para oferta dos EUA, cenário III.

\section{4_Conclusões}

A quantidade produzida de produtos como soja e açúcar reduziu-se com a abertura comercial. Isso decorre, em parte, porque as TECs do Mercosul são elevadas em relação às tarifas de outros países membros da Alca, em vários cenários e produtos. A redução dessas tarifas promoveu pequenas quedas na produção; a maior foi de $1,65 \%$ para a soja, no cenário em que ocorreu eliminação completa das tarifas. Também contribuiu para essa pequena queda na produção o fato de os EUA subsidiarem a produção de produtos como soja, algodão e milho. Nesse caso, a eliminação apenas das tarifas de importação não seria tão benéfica para o agronegócio do Brasil, o que requeriria uma posição mais agressiva do governo brasileiro quanto ao alto grau protecionista dos EUA à produção desses pro- dutos. No caso do agregado Oaindústria, ocorreu elevação na quantidade produzida, em todos os cenários.

Corroborando a idéia de baixa competitividade, o setor de manufaturados apresentou redução na produção e aumento menor das exportações do que das importações, em todos os cenários. Todavia, os manufaturados, como produtos florestais, têxteis e calçados, tiveram aumento significativo de produção, além de a quantidade exportada desses produtos, no geral, ter elevado mais do que suas importações. No entanto, dado o grande aumento nas importações dos manufaturados, maior que o crescimento das exportações, a balança comercial do Brasil foi deficitária em todos os cenários.

$\mathrm{O}$ indicador de crescimento econômico (PIB) cresceu em todos os cenários, para o Brasil, porém com elevações pequenas, visto que atingiu o máximo de 0,59\%. Logo, a criação da Alca não reduz, nem promove grandes melhorias, em termos de crescimento econômico e emprego, para a economia brasileira. Os indicadores de bem-estar, utilidade per capita e variação equivalente tiveram mudanças positivas, dado o aumento de consumo interno; entretanto, essas variações foram pequenas. 
Em quase todos os cenários de análise, as ofertas propostas pelos EUA tiveram maior impacto na economia brasileira, no que concerne a variações na produção, na exportação, na importação e nos preços. No entanto, nos indicadores de crescimento e bem-estar, Produto Interno Bruto, utilidade per capita e variação equivalente, do cenário III, as ofertas do Mercosul proporcionaram maiores ganhos para o Brasil, dado que, neste cenário, as ofertas dos EUA liberaram totalmente as tarifas de produtos não-agrícolas e quase $70 \%$ das tarifas de bens agrícolas, enquanto o Mercosul liberou cerca de $70 \%$ das tarifas dos bens agrícolas e apenas 50\% dos não-agrícolas. 


\section{Referências bibliográficas}

BERALDO, A. D. CNA insiste na retomada das negociações da ALCA em Puebla. Revista Gleba, n. 197 , p. 6-7, 2004.

CHIANG, A. C. Matemática para economistas. São Paulo:

Mcgraw-Hill, 1994.

CYPRIANO, L. A.; TEIXEIRA, E. C. Impactos da Área de Livre Comércio das Américas (ALCA), com e sem subsídios, na economia agrícola brasileira. In: REIS, B. S.; LÍRIO, V. S. (Ed.). Negociações internacionais e propriedade intelectual no agronegócio. Viçosa, UFV, 2001. p 49-82.

CYPRIANO, L. A.; TEIXEIRA, E. C. Impactos da Alca e do Mercoeuro no agronegócio do Mercosul. Revista de Economia e Sociologia Rural, v. 41, n. 2, p. 217-239, 2003.

FIGUEIREDO, M. R. F.; FERREIRA, A. V.; TEIXEIRA, E. C. Impacto da integração econômica nas commodities da econodmia brasileira e da União Européia. Revista Brasileira de Economia, v. 55, n. 1, p. 77-106, 2001
FERREIRA FILHO, J. B. S.; HORRIDGE, M. Economic integration, poverty and regional inequality in Brazil. In: 7th Annual conference on global economic analysis. Washington: World Bank and Center for Global Trade Analysis (Orgs.), 2004. Disponível em:

$<$ http://www.gtap.agecon .purdue.edu/events/conferences/ 2004/ default.asp >. Acesso em: 16 ago. 2006.

FONSECA, M. B.; HIDALGO, A. B (2004). Os impactos da ALCA sobre as exportações agrícolas brasileiras. Disponível em: <http:// www.anpec.org. br/encontro2004/artigos/A04A0 59.pdf>. Acesso em: 22 ago. 2006.

GEHLHAR, M.; HERTEL, T. W. Overview of the GTAP data base. In: HERTEL, T. W. (Ed.). Global trade analysis: modeling and applications. New York: Cambrige University, 1997. p. 74-124.

GURGEL, A. C.; CAMPOS, A. C. Alternativas de políticas comerciais para o agronegócio brasileiro sob diferentes pressuposições de retornos à escala. Revista de Economia e Agronegócio. Viçosa: UFV, v. 1, n. 2, p. $133-154,2003 \mathrm{a}$.
GURGEL A. C; CAMPOS A. C. Impactos da ALCA sobre o agronegócio brasileiro na presença de economias de escala e competição imperfeita. Pesquisa e Planejamento Econômico, v. 33, n. 3, p. 435-480, 2003b.

HARRISON, G. W. RUTHERFORD, T. F.; TARR, D. G.; GURGEL, A. Políticas de comércio regionais, multilaterais e unilaterais do Mercosul para o crescimento econômico e redução da pobreza no Brasil. Pesquisa e Planejamento Econômico, v. 33, p. 1-60, 2003.

HERTEL, T. W.; TSIGAS, M. E. Structure of GTAP. In: HERTEL, T. W. (Ed.). Global trade analysis: modeling and applications. New York: Cambridge University Press, p. 13-73, 1997.

\section{HORRIDGE, J. M.}

RunGTAP.EXE. Versão 3.41. Melbourne, Austrália: Centre of Policy Studies, Monash University, 2005.

LAIRD, S.; YEATS, A. The UNCTAD trade policy simulation model: a note on the methodology, data and uses. Geneva: UNCTAD, 1986. (Discussion Papers, n. 19).

\section{MINISTÉRIO DO} DESENVOLVIMENTO, INDÚSTRIA E COMÉRCIO MDIC (2005). TEC - Tarifa Externa Comum. Disponível em: $<$ http: www.mdic.gov.br>. Acesso em: 18 out. 2005.

VALVERDE, S. R.; TEIXEIRA, E. C. Impactos dos acordos da Rodada do Uruguai, Mercosul e Área de Livre Comércio das Américas (Alca) no comércio internacional. In: VIEIRA, W.; CARVALHO, F. (Ed (s).).

Mercosul: agronegócios e

desenvolvimento econômico. Viçosa, UFV, 1997. p. 47-62.

VARIAN, H. R. Microeconomia: princípios básicos - uma abordagem moderna. Rio de Janeiro, Campus, 1993.

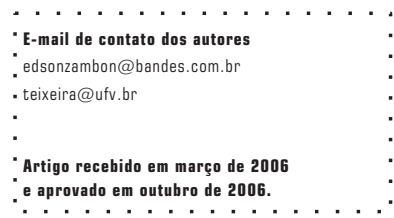

